\title{
Impaired hepatic autophagic activity in dairy cows with severe fatty liver is associated with inflammation and reduced liver function
}

\author{
Xiliang Du, ${ }^{* 1}$ Guowen Liu, ${ }^{* 1}$ Juan J. Loor, $\dagger^{1}$ Zhiyuan Fang, ${ }^{*}$ Ryan Bucktrout, $\dagger$ Yuchen Yang, ${ }^{*}$ Qianqian Ye, ${ }^{*}$ \\ Zhen Shi, ${ }^{*}$ Taiyu Shen, ${ }^{*}$ Xinghui Wang, ${ }^{*}$ Zhicheng Peng, ${ }^{*}$ Chenxu Zhao, ${ }^{*}$ Bin Lv, ${ }^{*}$ Dongmei Xing,‡ Yiwei Zhu, \\ Xiaobing $\mathrm{Li}^{*}$ and Xinwei $\mathrm{Li}^{* 2}$ \\ *Key Laboratory of Zoonosis, Ministry of Education, College of Veterinary Medicine, Jilin University, Changchun, Jilin Province, 130062, China \\ †Mammalian NutriPhysioGenomics, Department of Animal Sciences and Division of Nutritional Sciences, University of Illinois, Urbana 61801 \\ $\ddagger$ Animal Medicine College, Hunan Agriculture University, Changsha, Hunan, 410128, China
}

\begin{abstract}
The ability of liver to respond to changes in nutrient availability is essential for the maintenance of metabolic homeostasis. Autophagy encompasses mechanisms of cell survival, including capturing, degrading, and recycling of intracellular proteins and organelles in lysosomes. During negative nutrient status, autophagy provides substrates to sustain cellular metabolism and hence, tissue function. Severe negative energy balance in dairy cows is associated with fatty liver. The aim of this study was to investigate the hepatic autophagy status in dairy cows with severe fatty liver and to determine associations with biomarkers of liver function and inflammation. Liver and blood samples were collected from multiparous cows diagnosed as clinically healthy $(\mathrm{n}=15)$ or with severe fatty liver $(\mathrm{n}=15)$ at 3 to $9 \mathrm{~d}$ in milk. Liver tissue was biopsied by needle puncture, and serum samples were collected on 3 consecutive days via jugular venipuncture. Concentrations of free fatty acids and $\beta$-hydroxybutyrate were greater in cows with severe fatty liver. Milk production, dry matter intake, and concentration of glucose were all lower in cows with severe fatty liver. Activities of serum aspartate aminotransferase, alanine aminotransferase, glutamate dehydrogenase, and $\gamma$-glutamyl transferase were all greater in cows with severe fatty liver. Serum concentrations of haptoglobin and serum amyloid A were also markedly greater in cows with severe fatty liver. The mRNA expression of autophagosome formation-related gene ULK1 was lower in the liver of dairy cows with severe fatty liver. However, the expression of other autophagosome formation-related genes, beclin 1 (BECN1), phosphatidylinositol 3-kinase catalytic subunit type 3 (PIK3C3), autophagy-related gene $(A T G)$ 3, ATG5,
\end{abstract}

Received May 27, 2018.

Accepted August 30, 2018.

${ }^{1}$ These authors contributed equally to this paper.

${ }^{2}$ Corresponding author: lixinwei100@126.com and ATG12, did not differ. More important, ubiquitinated proteins, protein expression of sequestosome-1 (SQSTM1, also called p62), and microtubule-associated protein 1 light chain 3 (MAP1LC3, also called LC3)-II was greater in cows with severe fatty liver. Transmission electron microscopy revealed an increased number of autophagosomes in the liver of dairy cows with severe fatty liver. Taken together, these results indicate that excessive lipid infiltration of the liver impairs autophagic activity that may lead to cellular damage and inflammation.

Key words: liver lipidosis, autophagy, lactation, inflammation

\section{INTRODUCTION}

The transition period, roughly stretching from 3 wk before to 3 wk after parturition, is the most metabolically challenging period for dairy cows (Loor et al., 2013; Du et al., 2018b). Dry matter intake decreases gradually during the last 3 wk of gestation, whereas energy demands postpartum for maintenance of body functions and milk production are markedly higher than prepartum (Hayirli et al., 2002; Weber et al., 2013). As a result of this imbalance, cows mobilize fat and muscle depots to provide free fatty acids (referred to as fatty acids hereafter) and AA as fuels, helping alleviate the state of negative energy balance. However, high and sustained plasma concentrations of fatty acids can result in hepatic lipidosis and other clinical diseases such as ketosis and fatty liver syndrome (Loor et al., 2007). Consequently, adequate adaptation of metabolic pathways to support energy needs is particularly important for a successful transition period.

The liver plays a key role in coordination of nutrient flux in supporting pregnancy and lactation. In the 4 wk after calving, it is estimated that more than $50 \%$ of high-yielding dairy cows suffer from mild or moderate fatty liver and that 5 to $10 \%$ of dairy cows have severe fatty liver (Bobe et al., 2004). Dairy cows with severe 
fatty liver generally display disorders of lipid metabolism, liver damage, inflammation, and oxidative stress (Bobe et al., 2004; Loor et al., 2007; Song et al., 2016). In addition, treatment of severe fatty liver is much more difficult than treatment of mild or moderate fatty liver. Despite the fact that severe fatty liver is usually not lethal, most cows never regain full health and productivity and tend to relapse (Bobe et al., 2004). Although some studies have evaluated molecular adaptations occurring at the transcriptional (Loor et al., 2007) and protein (Kuhla et al., 2009) levels, additional mechanisms have not been assessed.

Regulation of the abundance of intracellular components via recycling is the basis of cellular survival, particularly during abrupt physiologic changes (Mizushima, 2005; Singh and Cuervo, 2011). Autophagy (Greek for "self-eating") is a highly conserved recycling process that involves degradation of cellular constituents in lysosomes (Mizushima et al., 2008). A growing body of evidence has revealed that autophagy contributes to basic hepatic functions, including regulation of lipid accumulation and $\beta$-oxidation (Schiaffino et al., 2008; Martinez-Lopez and Singh, 2015; Ueno and Komatsu, 2017). As an adaptative catabolic process under nutrient-deficient conditions, autophagy could generate energy for cells (Lum et al., 2005; Yorimitsu and Klionsky, 2005). However, failure to properly execute the autophagic program could render hepatocytes vulnerable to stressors and unable to accommodate the energetic demands of the organism (González-Rodríguez et al., 2014; Liu et al., 2016; Ueno and Komatsu, 2017).

Previous studies demonstrated that humans and mice with fatty liver display dysregulation of hepatic autophagy (Yang et al., 2010; Kim et al., 2013; GonzálezRodríguez et al., 2014). More important, defective hepatic autophagy promotes fatty liver in mice (Yang et al., 2010). Therefore, impaired hepatic autophagy may be associated with the occurrence and development of fatty liver. Dairy cows with fatty liver are characterized by negative energy balance, ectopic lipid accumulation, and disorders of lipid metabolism (Esposito et al., 2014; Li et al., 2015; Song et al., 2016). However, the status of hepatic autophagy in dairy cows with severe fatty liver has not been reported previously. Therefore, the aim of this study was to investigate the status of hepatic autophagy in dairy cows with severe fatty liver.

\section{MATERIALS AND METHODS}

\section{Animals}

The Ethics Committee on the Use and Care of Animals at Jilin University approved the study protocol [Changchun, China, 2017 clinical trial (2017-0306)]. To
Table 1. Ingredient and nutrient composition of the diets

\begin{tabular}{|c|c|}
\hline Item (\% of DM unless otherwise indicated) & Value \\
\hline \multicolumn{2}{|l|}{ Ingredient } \\
\hline Corn silage & 40 \\
\hline Corn & 35 \\
\hline Wheat bran & 8 \\
\hline Soybean meal & 5 \\
\hline Sunflower & 8 \\
\hline $\mathrm{NaCl}$ & 1 \\
\hline Premix $^{1}$ & 1.8 \\
\hline $\mathrm{NaHCO}_{3}$ & 1.2 \\
\hline Total & 100 \\
\hline \multicolumn{2}{|l|}{ Nutrient composition } \\
\hline $\mathrm{NE}_{\mathrm{L}}(\mathrm{MJ} / \mathrm{kg})$ & 6.7 \\
\hline $\mathrm{CP}$ & 15.2 \\
\hline $\mathrm{NDF}$ & 33.45 \\
\hline $\mathrm{ADF}$ & 17.2 \\
\hline $\mathrm{NFC}$ & 40.4 \\
\hline $\mathrm{Ca}$ & 0.7 \\
\hline $\mathrm{P}$ & 0.5 \\
\hline
\end{tabular}

${ }^{1}$ One kilogram of premix contained the following: vitamin A, 200,000 IU; vitamin D, 70,000 IU; vitamin E, 1,000 IU; Fe, 2,000 mg; Cu, 600 $\mathrm{mg}$; Zn, 2,400 mg; Mn, 1,300 mg; I, 6 mg; Co, $7 \mathrm{mg}$.

ensure that cows were free of comorbidities, they received a routine physical examination. All cows had ad libitum access to the same diets. The basal diet formulation is shown in Table 1. We chose lactating Holstein cows with similar numbers of lactations (median $=3$, range $=2-4$ ) and DIM (median $=6 \mathrm{~d}$, range $=3-9$ d) from a 1,000-cow dairy farm located in Changchun (Jilin Province, China). Fifteen healthy Holstein cows and 15 cows with severe fatty liver were selected based on liver triacylglycerol (TAG) content (i.e., $1 \% \mathrm{~g} / \mathrm{g}$ of wet weight; Bobe et al., 2004) hepatic TAG for healthy cows and $>10 \%$ TAG in cows with severe fatty liver. The BCS was assigned based on a 1- to 5-point scale according to previous reports (Edmonson et al., 1989). The basic description of the cows is shown in Table 2 .

Cows were milked twice daily at 0530 and $1500 \mathrm{~h}$, milk yield was recorded, and milk samples were collected at each milking on 3 consecutive days. Milk samples were stored at $4^{\circ} \mathrm{C}$ with a preservative $(1 \mathrm{mg} /$ $\mathrm{mL}$ of potassium dichromate) before infrared analysis for fat, protein, and lactose (Foss MilkoScan, Foss Food Technology Co., Eden Prairie, MN). Blood samples were collected on 3 consecutive days via jugular venipuncture (no anticoagulant) between 0700 and $0800 \mathrm{~h}$ before feeding and immediately centrifuged at 3,500 $\times$ $g$ for $15 \mathrm{~min}$ at $4^{\circ} \mathrm{C}$. The serum was obtained and stored at $-80^{\circ} \mathrm{C}$ until analysis.

\section{Liver Tissue Collection}

Liver tissue was biopsied twice from the 11th or 12th right intercostal space by needle puncture (Shanghai Surgical Equipment Factory, Shanghai, China) after 
Table 2. Body weight, BCS, milk production, DMI, and milk composition of healthy (control) cows and cows with severe fatty liver

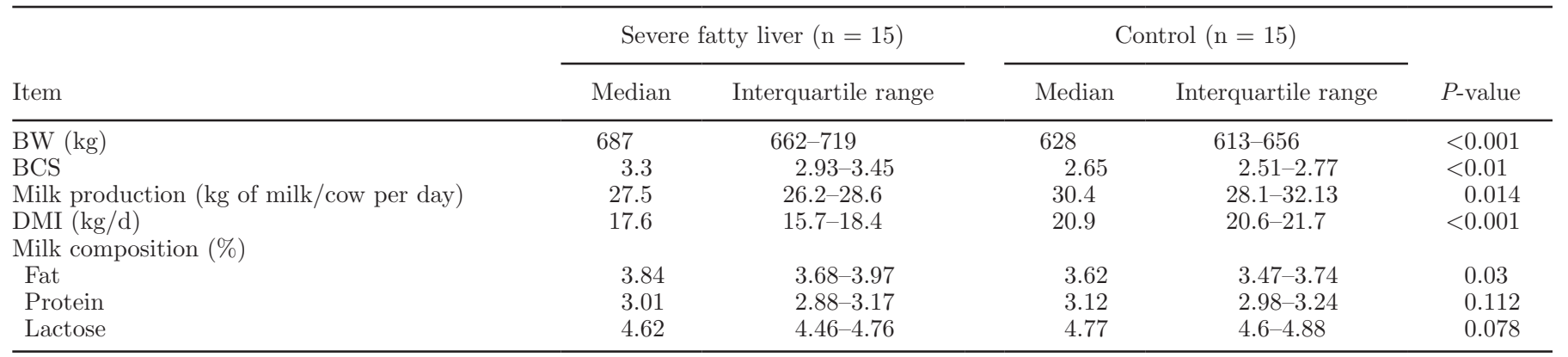

blood collection (Du et al., 2017a). Before liver biopsy, the intercostal space was shaved, sanitized with iodine scrub and $75 \%$ alcohol, and anesthetized with subcutaneous injection of $2 \%$ lidocaine $\mathrm{HCl}$ (Sigma-Aldrich Co., St. Louis, MO). A scalpel blade was used to make a 3-mm stab incision in the skin. The biopsy needle was then inserted through the intercostal muscle layers and into the liver. Tissue ( $\sim 170 \mathrm{mg}$ from each puncture) was immediately frozen in liquid nitrogen and a subsample was fixed with $10 \%$ formaldehyde neutral buffer solution, optimal cutting temperature compound (Sakura Finetek Co., Torrance, CA), or $2.5 \%$ glutaraldehyde and $2 \%$ paraformaldehyde. During the experimental work, the cows were housed in tiestall barns.

\section{Blood Assays}

Concentrations of glucose, BHB, and fatty acids in serum were determined using a Hitachi 7170 autoanalyzer (Hitachi, Tokyo, Japan) with commercially available kits (BHB: RB1008; fatty acids: FA115; glucose: GL3815; Randox Laboratories, Crumlin, UK). The activities of aspartate aminotransferase (AST), alanine aminotransferase (ALT), glutamate dehydrogenase (GLDH), and $\gamma$-glutamyl transferase (GGT) were determined using an automatic biochemistry analyzer (Sekisui Medical Co. Ltd., Tokyo, Japan) with commercially available kits (AST: AS3804; ALT: AL3801; GLDH: GL442; GGT: GT3817; Randox Laboratories).

\section{ELISA}

The concentrations of haptoglobin (HP) and serum amyloid A (SAA) were determined using bovine-specific ELISA kits (HP: GWB-A43096, GenWay Biotech, San Diego, CA; SAA: LS-F12552, LifeSpan BioSciences Inc., Seattle, WA) according to the manufacturer's instructions. The intra- and interassay coefficients of variation were less than 7.0 and $5.1 \%$, respectively, for $\mathrm{HP}$ and 10 and $12 \%$, respectively, for SAA. The test sensitivity of HP and SAA was 6.258 and $3.12 \mathrm{ng} /$
$\mathrm{mL}$, respectively. Every serum sample was analyzed in triplicate, and absorbance values were read at $450 \mathrm{~nm}$ for HP and SAA using a spectrophotometer (Thermo Fisher Scientific, Shanghai, China).

\section{Liver Histology}

Liver tissue was fixed in $10 \%$ formaldehyde neutral buffer solution, embedded in paraffin, and cut into $8 \mu \mathrm{m}$. Slides were dewaxed with xylene, rehydrated through descending concentrations of alcohol, and stained with hematoxylin and eosin. For oil-red $\mathrm{O}$ staining, liver tissues were frozen in optimal cutting temperature compound (Sakura Finetek Co.), sectioned to $8 \mu \mathrm{m}$ at $-18^{\circ} \mathrm{C}$, and fixed with $75 \%$ alcohol at room temperature for $15 \mathrm{~min}$. Slides were then stained with oil-red $\mathrm{O}$ and counterstained with hematoxylin.

\section{Immunohistochemistry}

Liver immunohistochemistry was performed as described previously (Li et al., 2011). Briefly, paraffinembedded liver sections were deparaffinized and rehydrated in graded alcohol. A heat-induced epitope retrieval technique was used by boiling liver sections in a solution of $10 \mathrm{mM}$ citrate buffer ( $\mathrm{pH} \mathrm{6.0)}$ for $2 \mathrm{~min}$ in a microwave 3 times. Endogenous peroxidase activity was quenched by the incubation in $3 \%$ hydrogen peroxide for $10 \mathrm{~min}$. Slides were then blocked with $10 \%$ normal goat serum (AR0009; Boster Biological Technology Co. Ltd., Wuhan, China) in PBS for $30 \mathrm{~min}$. Slides were incubated with an antibody to sequestosome-1 (SQSTM1, also called p62; ab101266; Abcam, Cambridge, MA; diluted 1:500 with PBS containing 5\% goat serum) overnight at $4^{\circ} \mathrm{C}$. The specificity of staining was examined by omission of primary antibodies. The slides were subsequently incubated with a horseradish peroxidase-conjugated antirabbit immunoglobulin at room temperature for $45 \mathrm{~min}$. Last, the sections were stained with diaminobenzidine and counterstained with hematoxylin, and images were acquired (Olympus, To- 
kyo, Japan). Positive as well as negative control slides were included in every experiment.

\section{Transmission Electron Microscopy}

The ultrastructural characteristics of autophagosomes were visualized by transmission electron microscopy (Lei et al., 2016; Du et al., 2018a). Liver biopsies were fixed with $2.5 \%$ glutaraldehyde and $2 \%$ paraformaldehyde at $4^{\circ} \mathrm{C}$ for $12 \mathrm{~h}$ and then postfixed in $1 \%$ osmium tetroxide for $1 \mathrm{~h}$. Subsequently, liver biopsies were dehydrated in an ethanol series and infiltrated with Spurr's resin. Ultrathin sections $(50 \mathrm{~nm})$ were cut and stained with $4 \%$ uranyl acetate and $0.2 \%$ lead citrate. Observations were performed on an H-7650 electron microscope (Hitachi, Japan). Autophagosomes were quantified as previously described (Backues et al., 2014). Autophagosomes were counted from at least 15 random cells in each sample and expressed as the number of autophagosomes per cell.

\section{TAG Content Determination}

Liver tissue $(\sim 20 \mathrm{mg})$ was homogenized in $5 \%$ triton$\mathrm{X} 100$ and then heated in a water bath $\left(85^{\circ} \mathrm{C}\right)$ for 3 min. After cooling at room temperature, samples were vortexed and centrifuged at $2,000 \times g$ for $5 \mathrm{~min}$ at $4^{\circ} \mathrm{C}$. The supernatant was collected and stored at $-80^{\circ} \mathrm{C}$ before TAG assay. The TAG content was measured using an enzymatic kit (E1013; Applygen Technologies, Beijing, China) following the manufacturer's instructions. Total protein concentration was estimated by the bicinchoninic acid method (P1511; Applygen Technologies).

\section{Quantitative Reverse-Transcription PCR Assay}

The total RNA from liver tissue $(\sim 20 \mathrm{mg})$ was extracted using RNAiso Plus (TaKaRa Biotechnology Co. Ltd., Dalian, China) according to the manufacturer's instructions. The RNA concentration and quality were measured using a K5500 microspectrophotometer (Beijing Kaiao Technology Development Ltd., Beijing, China) and electrophoresis (1\% agarose gels). Then, 1 $\mu \mathrm{g}$ of total RNA in each sample was reverse transcribed to cDNA in $20-\mu \mathrm{L}$ reactions using a reverse transcription kit (TaKaRa Biotechnology Co. Ltd.) according to the supplier's protocol.

We evaluated mRNA expression level using quantitative reverse-transcription PCR (qRT-PCR) technology with the SYBR Green QuantiTect RT-PCR kit (TaKaRa Biotechnology Co. Ltd.) and a 7500 real-time PCR system (Applied Biosystems Inc., Waltham, MA). The qRT-PCR was conducted under the following con- ditions: initial denaturation at $94^{\circ} \mathrm{C}$ for 2 min, 35 cycles of amplification (denaturation at $94^{\circ} \mathrm{C}$ for $10 \mathrm{~s}$, annealing at $60^{\circ} \mathrm{C}$ for $15 \mathrm{~s}$, and extension at $72^{\circ} \mathrm{C}$ for $30 \mathrm{~s}$ ), and extension at $72^{\circ} \mathrm{C}$ for $5 \mathrm{~min}$.

The relative expression of each target gene was normalized to 3 reference genes - actin $\beta(A C T B)$, glyceraldehyde-3-phosphate dehydrogenase $(G A P D H)$, and ATP synthase $(A T P 5 B)$ - and calculated using the $2^{-\Delta \Delta \mathrm{CT}}$ method. The qRT-PCR reaction was performed in triplicate for each of the 15 cows per group. The primers used for Unc-51-like kinase 1 (ULK1), beclin 1 (BECN1), phosphatidylinositol 3-kinase catalytic subunit type 3 (PIK3C3), autophagy-related gene (ATG) 3, ATG5, ATG12, SQSTM1, microtubule-associated protein 1 light chain 3 (MAP1LC3, also called $L C 3)$, and $A C T B$ are shown in Table 3. The cycles-tothreshold values of $A C T B, G A P D H$, and $A T P 5 B$ were not affected by fat content, findings that validated its usefulness as a control gene (Connor et al., 2010; Morey et al., 2011; Du et al., 2017a; Supplemental Figure S1; https://doi.org/10.3168/jds.2018-15120).

\section{Western Blotting}

Western blotting was performed as previously described (Du et al., 2017b; Sun et al., 2017). Total liver $(\sim 30 \mathrm{mg})$ protein was extracted using a protein extraction kit (C510003; Sangon Biotech Co. Ltd., Shanghai, China). Total protein concentration was estimated by the bicinchoninic acid method (P1511; Applygen Technologies). A total of $30 \mu \mathrm{g}$ of protein from each sample was separated by $12 \%$ SDS-PAGE and electrophoretically transferred to a polyvinylidene difluoride membrane. The membranes were blocked in 3\% BSA/ Tris-buffered saline/Tween (TBS-T) buffer for $4 \mathrm{~h}$. The blocked membranes were incubated overnight at $4^{\circ} \mathrm{C}$ with primary antibodies against p62 (1:2,000; ab101266; Abcam), LC3 (1:1,000; ab48394; Abcam), $\beta$-actin (1:2,000; ab8226; Abcam), or ubiquitin (1:200; sc-271289; Santa Cruz Biotechnology, Santa Cruz, CA). The membranes were then washed with TBS-T and incubated with horseradish peroxidase-conjugated antirabbit or antimouse immunoglobulin at room temperature for $45 \mathrm{~min}$. Immunoreactive bands were visualized by enhanced chemiluminescence solution (ECL, Millipore, Bedford, MA). $\beta$-Actin was used a reference protein in this study, and each band was related to $\beta$-actin. All bands were analyzed using Image-Pro Plus (Media Cybernetics, Rockville, MD).

\section{Statistical Analysis}

All experiments were repeated at least 3 times. Data for hepatic TAG content, Western blotting, and qRT- 
Table 3. Primers used during quantitative reverse-transcription PCR assay

\begin{tabular}{|c|c|c|c|c|c|}
\hline Gene $^{1}$ & $\operatorname{Primer}^{2}\left(5^{\prime}-3^{\prime}\right)$ & $\begin{array}{l}\text { Location on } \\
\text { template (bp) }\end{array}$ & GenBank no. & $\begin{array}{l}\text { Length } \\
\text { (bp) }\end{array}$ & $\begin{array}{c}\text { Annealing } \\
\text { temperature }\left({ }^{\circ} \mathrm{C}\right)\end{array}$ \\
\hline$A C T B$ & F: CCTGCGGCATTCACGAAACTAC & F: $904-925$ & NM_173979.3 & 273 & 60 \\
\hline$G A P D H$ & R: TCATGGATGACCTTGGCCAG & R: $543-562$ & & & \\
\hline \multirow[t]{2}{*}{$A T P 5 B$} & F: GGACTCAGCCCTTCAGCGCC & F: $74-93$ & NM_175796.3 & 229 & 60 \\
\hline & R: GCCTGGTCTCCCTGCCTTGC & R: $283-302$ & & & \\
\hline \multirow[t]{2}{*}{ LC3 } & F: TGAGAAACAGCTTCCTGTCC & F: $161-180$ & NM_001001169.1 & 158 & 60 \\
\hline & R: TGGACACACTCACCATGCTA & R: $299-318$ & & & \\
\hline \multirow[t]{2}{*}{$U L K 1$} & F: CACTATGACGGGAAGGCAG & F: $745-763$ & NM_001205927.1 & 113 & 60 \\
\hline & R: TCGTAGAAGAGGCGGAGGT & R: $839-857$ & & & \\
\hline \multirow[t]{2}{*}{$B E C N 1$} & F: GCTCAGTATCAAAGGGAAT & F: $810-828$ & NM_001033627.2 & 99 & 60 \\
\hline & R: CATCTGGGCATAACGCATC & R: $908-890$ & & & \\
\hline РIКЗС3 & F: GCCAAGCATTGTTGAAGGGT & F: $1,632-1,651$ & NM_001099067.1 & 87 & 60 \\
\hline \multirow[t]{2}{*}{ ATG12 } & F: GTAGAGCGAACCCGAACCAT & F: $240-259$ & NM_001076982.1 & 154 & 60 \\
\hline & R: CACTGCCAAAACACTCATAG & R: $374-393$ & & & \\
\hline
\end{tabular}

${ }^{1} A C T B=\beta$-actin; $G A P D H=$ glyceraldehyde-3-phosphate dehydrogenase; $A T P 5 B=$ adenosine triphosphate synthase; $S Q S T M 1=$ sequestosome-1; $L C 3=$ microtubule-associated protein 1 light chain $3 ; U L K 1=$ Unc-51-like kinase $1 ; B E C N 1=$ beclin $1 ; P I K 3 C 3=$ phosphatidylinositol 3-kinase catalytic subunit type 3; ATG3 = autophagy-related gene 3; ATG5 = autophagy-related gene 5; ATG12= autophagy-related gene 12 . ${ }^{2} \mathrm{~F}=$ forward; $\mathrm{R}=$ reverse.

PCR were normally distributed and analyzed with paired $t$-tests; other data were not normally distributed and were analyzed with a Wilcoxon signed rank test. All analyses were performed using GraphPad Prism 5.0 (Graph Pad Software, San Diego, CA) or SPSS 19.0 software (IBM, Chicago, IL). Baseline characteristics and blood parameters are expressed as the median and interquartile range, and other data are expressed as the mean \pm standard error of the mean; $P<0.05$ was considered statistically significant.

\section{RESULTS}

\section{Liver TAG Content}

Content of TAG in cows with severe fatty liver was greater $(P<0.001)$ than that in healthy cows (Figure 1A). Furthermore, cows with severe fatty liver displayed significant lipid accumulation as demonstrated by hematoxylin and eosin and oil-red $\mathrm{O}$ (Figure 1B and $\mathrm{C}$ ).

\section{Baseline Characteristics}

Body weight and BCS of dairy cows with severe fatty liver was markedly greater $(P<0.001$ and $P<$ 0.05 , respectively) than that of healthy cows (Table 2). However, milk production and DMI of cows with severe fatty liver was lower $(P<0.05$ and $P<0.001$, respectively) than that of healthy cows (Table 2 ). In addition, milk fat percentage of cows with severe fatty liver was greater $(P<0.05)$ than that of healthy cows (Table 2). The percentages of milk protein and lactose did not differ between groups (Table 2).

\section{Blood Parameters}

Concentrations of fatty acids and BHB were greater $(P<0.001$ and $P<0.001$, respectively $)$ in cows with severe fatty liver than in healthy cows (Table 4). In contrast, concentration of glucose was markedly lower $(P<0.001)$ in cows with severe fatty liver than in healthy cows (Table 4).

The activities of AST, ALT, GLDH, and GGT were all greater $(P<0.001)$ in the serum of cows with severe fatty liver than in healthy cows (Table 4 ). Furthermore, concentrations of inflammation biomarkers HP and SAA were also markedly greater $(P<0.001)$ in cows with severe fatty liver than in healthy cows (Table 4 ).

\section{Expression of Autophagosome Formation-Related Genes}

The expression of $U L K 1$ was lower $(P<0.05)$ in the liver of cows with severe fatty liver than in healthy 

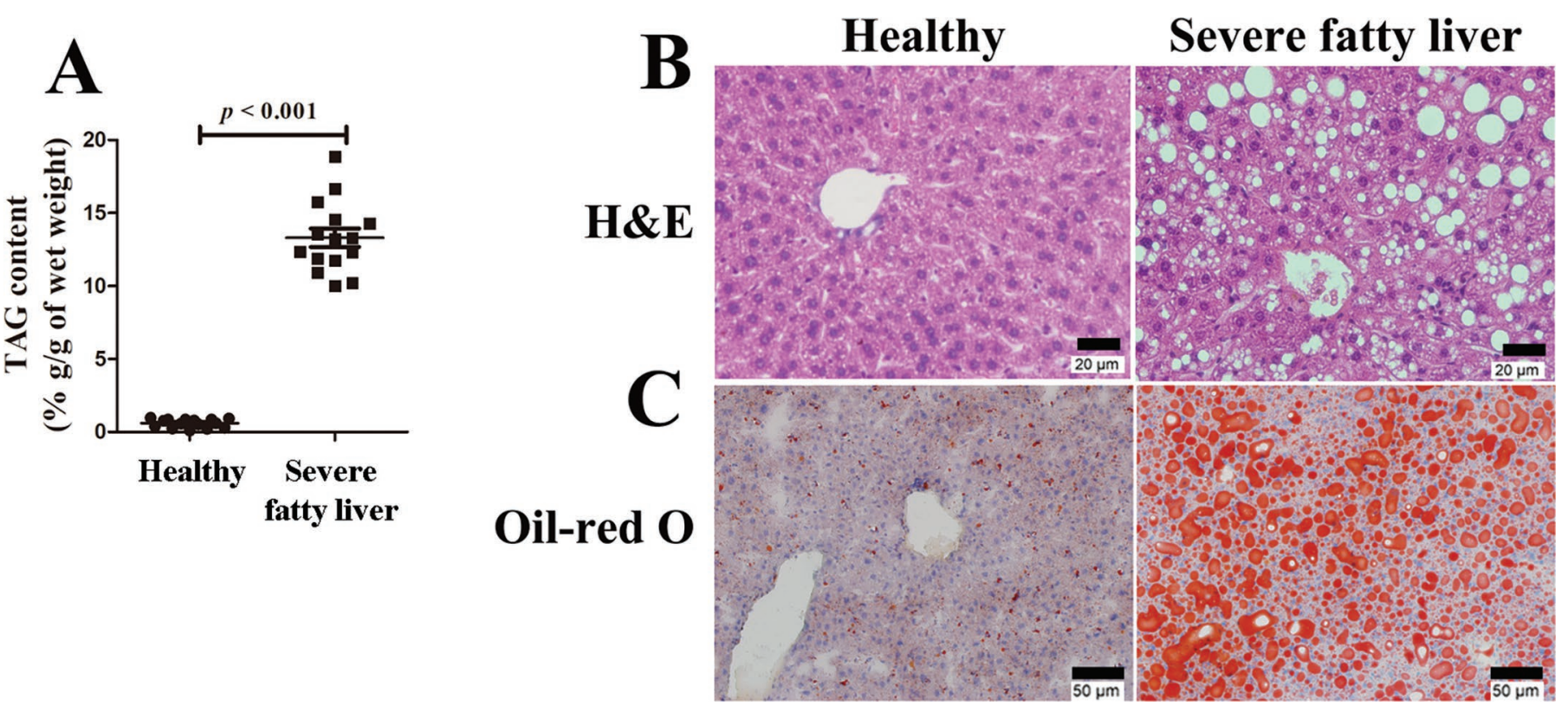

Figure 1. Liver histology and triacylglycerol content. (A) Hepatic triacylglycerol (TAG) content in healthy cows $(\mathrm{n}=15)$ and cows with severe fatty liver $(\mathrm{n}=15)$. (B, C) Representative images of hematoxylin and eosin $(\mathrm{H} \& \mathrm{E})$ and oil-red O staining of liver sections, respectively. The TAG content was analyzed with paired $t$-tests and expressed as the mean \pm SEM. Color version available online.

cows (Table 5). However, the expression of BECN1, PIK3C3, ATG3, ATG5, and ATG12 did not differ between groups (Table 5).

\section{Changes of Hepatic Autophagic Activity}

Ubiquitinated proteins accumulated $(P<0.05)$ in the liver of cows with severe fatty liver compared with healthy cows (Figure 2). Furthermore, the protein expression of $\mathrm{p} 62$, which is required for autophagic degradation of ubiquitinated proteins, was also significantly greater $(P<0.05)$ in the liver of cows with severe fatty liver (Figure 3A and C). Immunohistochemistry staining of p62 revealed similar results (Figure 4). It is noteworthy that hepatic mRNA expression of SQSTM1 did not differ between groups (Table 5). Despite a lack of difference in mRNA expression (Table 5), expression of LC3-II protein was greater $(P<0.05)$ in the liver of cows with severe fatty liver than in the liver of healthy cows (Figure 3A and B). Transmission electron microscopy revealed an increase $(P<0.001)$ in the number of autophagosomes in the liver of cows with severe fatty liver (Figure 5).

\section{DISCUSSION}

Autophagic activity, a dynamic process, encompasses the formation of autophagosomes, inclusion of cargo

Table 4. Serum concentrations of glucose, fatty acids, BHB, liver damage markers, and inflammation markers in healthy cows and cows with severe fatty liver

\begin{tabular}{|c|c|c|c|c|c|}
\hline \multirow[b]{2}{*}{ Item $^{1}$} & \multicolumn{2}{|c|}{ Severe fatty liver $(\mathrm{n}=15)$} & \multicolumn{2}{|c|}{ Control $(\mathrm{n}=15)$} & \multirow[b]{2}{*}{$P$-value } \\
\hline & Median & Interquartile range & Median & Interquartile range & \\
\hline Fatty acids $(\mathrm{m} M)$ & 1 & $0.82-1.2$ & 0.4 & $0.23-0.52$ & $<0.001$ \\
\hline $\mathrm{BHB}(\mathrm{m} M)$ & 2.77 & $2.06-3.36$ & 0.46 & $0.35-0.6$ & $<0.001$ \\
\hline $\operatorname{AST}(\mathrm{U} / \mathrm{L})$ & 130.69 & $117.46-145.56$ & 74.63 & $65.46-83.9$ & $<0.001$ \\
\hline ALT (U/L) & 28.18 & $24.7-32.96$ & 17.33 & $15.58-23.24$ & $<0.001$ \\
\hline GLDH (U/L) & 44.1 & $35.7-49.3$ & 20.9 & $17.6-23.3$ & $<0.001$ \\
\hline GGT (U/L) & 25.6 & $19.92-31.68$ & 13 & $11.01-13.73$ & $<0.001$ \\
\hline
\end{tabular}

${ }^{1} \mathrm{AST}=$ aspartate aminotransferase; ALT = alanine aminotransferase; HP = haptoglobin; SAA = serum amyloid A; GLDH = glutamate dehydrogenase; GGT $=\gamma$-glutamyl transferase. 

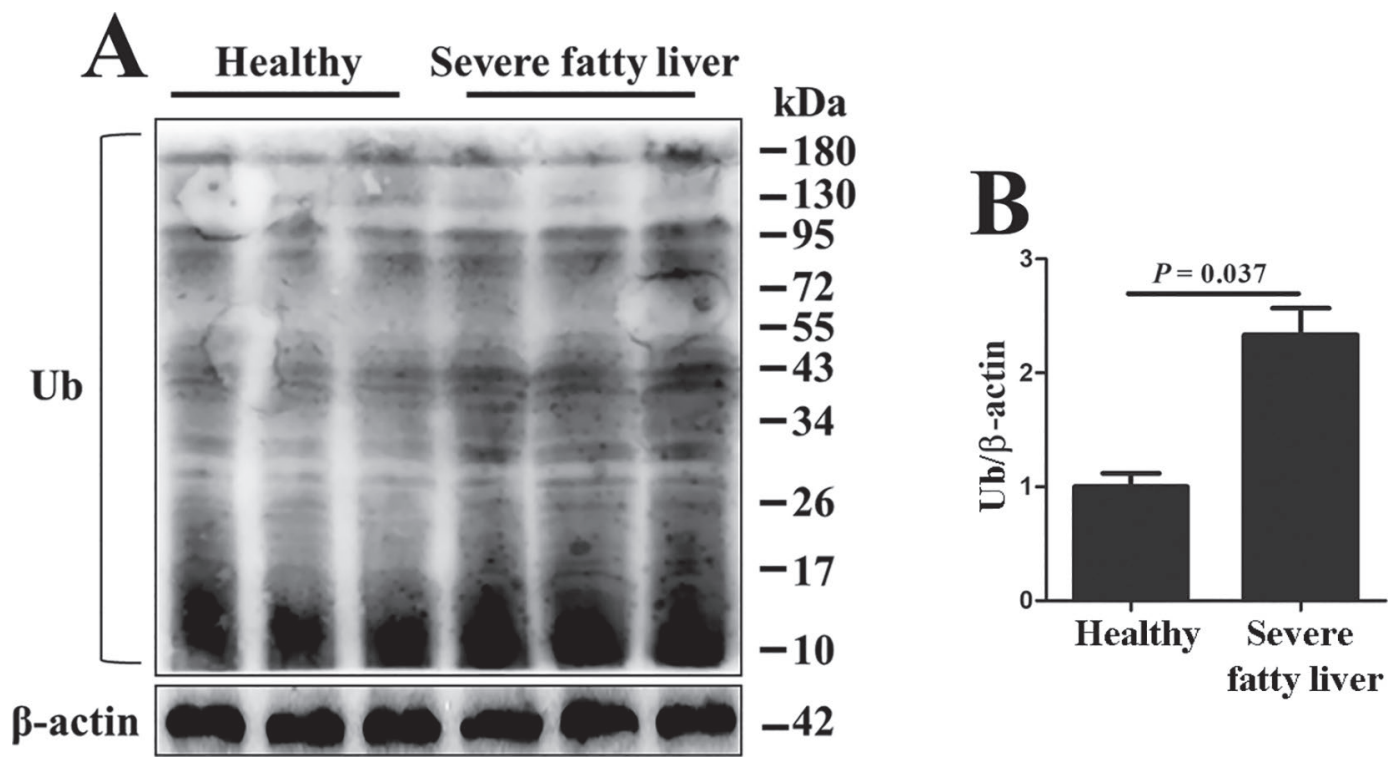

Figure 2. Expression of ubiquitinated proteins. (A) Hepatic expression of ubiquitinated proteins in healthy cows $(\mathrm{n}=15)$ and cows with severe fatty liver $(\mathrm{n}=15)$. Representative blots are shown. (B) Quantification of hepatic expression of ubiquitinated proteins. Data were analyzed with paired $t$-tests and expressed as the mean \pm SEM. Ub $=$ ubiquitin.

with the autophagosome, fusion of autophagosomes and lysosomes, and their subsequent breakdown with the release of macromolecules back into the cytosol (Loos et al., 2014). Previous studies demonstrated that fatty liver impaired hepatic autophagic activity in humans and mice (Yang et al., 2010; Kim et al., 2013; GonzálezRodríguez et al., 2014). However, the role of autophagy in dairy cows afflicted by severe fatty liver is not fully understood. In this study, abundance of ubiquitinated proteins, protein expression of p62 and LC3-II, and the number of autophagosomes were all increased in liver from cows with severe fatty liver, indicating impaired hepatic autophagic activity. Furthermore, the blood concentrations of inflammation and liver damage bio-

Table 5. Relative mRNA abundance (mean \pm SEM) of autophagyrelated genes

\begin{tabular}{lccc}
\hline Gene $^{1}$ & $\begin{array}{c}\text { Severe fatty } \\
\text { liver }(\mathrm{n}=15)\end{array}$ & $\begin{array}{c}\text { Control } \\
(\mathrm{n}=15)\end{array}$ & $P$-value \\
\hline ULK1 & $0.83 \pm 0.04$ & $1 \pm 0.06$ & 0.022 \\
BECN1 & $1.13 \pm 0.05$ & $1 \pm 0.04$ & 0.078 \\
PIK3C3 & $1.09 \pm 0.05$ & $1 \pm 0.05$ & 0.22 \\
ATG3 & $1.1 \pm 0.05$ & $1 \pm 0.05$ & 0.108 \\
ATG5 & $0.88 \pm 0.07$ & $1 \pm 0.04$ & 0.087 \\
ATG12 & $0.94 \pm 0.08$ & $1 \pm 0.08$ & 0.519 \\
LC3 & $1.27 \pm 0.09$ & $1 \pm 0.04$ & 0.059 \\
SQSTM1 & $1.25 \pm 0.05$ & $1 \pm 0.05$ & 0.177 \\
\hline
\end{tabular}

${ }^{1} U L K 1=$ Unc-51-like kinase $1 ; B E C N 1=$ beclin $1 ;$ PIK3C3 $=$ phosphatidylinositol 3-kinase catalytic subunit type 3; ATG3 = autophagyrelated gene 3; ATG5 = autophagy-related gene 5; ATG12 = autophagy-related gene $12 ; L C 3=$ microtubule-associated protein 1 light chain 3; SQSTM1 = sequestosome-1. markers were also increased in cows with severe fatty liver, suggesting a potential link between impaired hepatic autophagic activity and control of inflammation and liver damage.
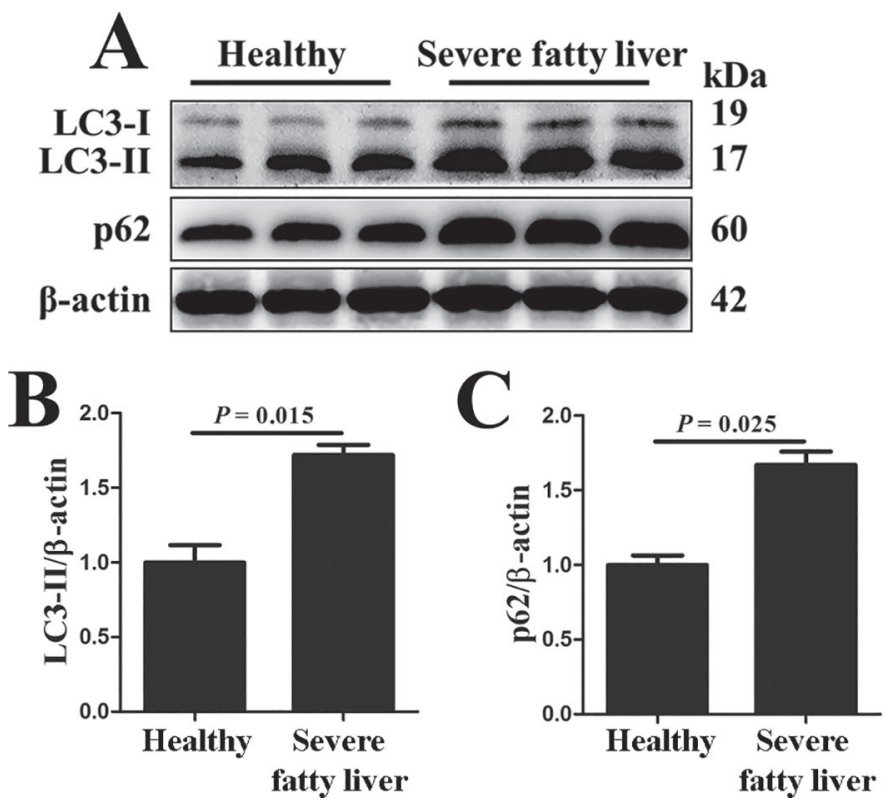

Figure 3. Hepatic autophagy status. (A) Hepatic protein levels of microtubule-associated protein 1 light chain 3 (LC3) and sequestosome-1 (p62) in healthy cows $(n=15)$ and cows with severe fatty liver $(\mathrm{n}=15)$. Representative blots are shown. $(\mathrm{B}, \mathrm{C})$ Quantification of hepatic protein levels of LC3-II and p62, respectively. Data were analyzed with paired $t$-tests and expressed as the mean \pm SEM. 
Impaired autophagy has been shown to be involved in the pathogenesis of fatty liver in humans and mice (Madrigal-Matute and Cuervo, 2016; Tanaka et al., 2016). González-Rodríguez et al. (2014) reported that autophagic activity was impaired in livers from both patients and murine models of nonalcoholic fatty liver disease. Downregulation of certain autophagic pathway proteins can cause fatty liver and insulin resistance in mice (Yang et al., 2010). More important, induction of autophagy prevents hepatic lipid accumulation in mice (Liu et al., 2016). Our data indicating that autophagic activity was impaired in dairy cows with severe fatty liver underscore the vital role of autophagy in cow liver. The positive association between blood fatty acids concentration and degree of lipid infiltration of dairy cows is well established (Bobe et al., 2004). Because high concentrations of fatty acids inhibit the autophagic activity in Huh7 and HepG2 cells (González-Rodríguez et al., 2014; Miyagawa et al., 2016), it could be possible that a similar mechanism exists in dairy cows. Therefore, the high blood concentrations of fatty acids and hepatic TAG content we detected in cows with severe fatty liver might be functionally related to impaired hepatic autophagic activity.

When nutrients are scarce, autophagic degradation of abnormal or damaged hepatic proteins, organelles, and lipid droplets can be recycled for synthesis of new cellular components or further oxidized to generate ATP (Schneider and Cuervo, 2014). Several studies demonstrated that lipophagy, degradation of lipids via autophagy, contributed directly to hepatic lipid catabolism and decreased lipid accumulation (Liu et

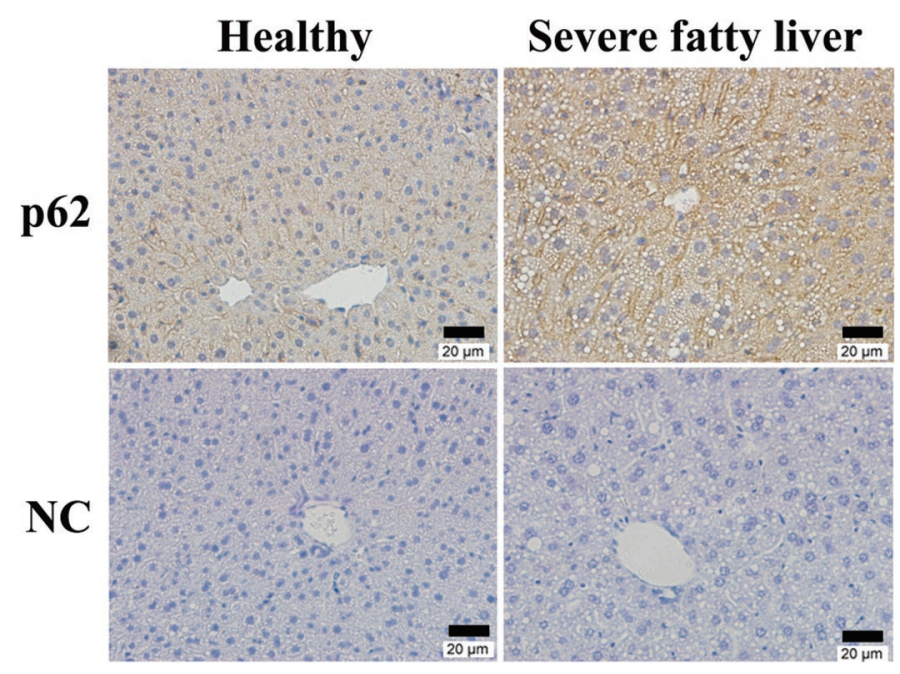

Figure 4. Hepatic immunohistochemistry staining of sequestosome-1 (p62). Representative images of hepatic immunohistochemistry staining of $\mathrm{p} 62$ in healthy cows and cows with severe fatty liver. $\mathrm{NC}=$ negative control. Color version available online. al., 2016; Martinez-Lopez et al., 2016; Sathyanarayan et al., 2017). Therefore, increasing autophagic activity may be an efficient way to overcome energy deficiency and lipid accumulation. Impaired autophagic activity during fatty liver may further aggravate the energydeficient state and contribute to excessive hepatic lipid accumulation.

At least in nonruminants, the process of cellular autophagy is activated in energy-deficient states, during which the degradation of cellular constituents provides substrates for the production of ATP (Sciarretta et al., 2013). Dairy cows with severe fatty liver generally experience marked negative energy balance. Accordingly, we speculated that autophagosome formation might be increased in the liver of dairy cows with severe fatty liver. However, decreased expression of $U L K 1$ and the lack of difference in expression of BECN1, PIK3C3, ATG3, ATG5, ATG12, and LC3 indicated no major effect of fatty liver on autophagosome formation. Several studies have reported that protein expression of ULK1, BECN1, and ATG5 were not altered in the liver of mice with fatty liver induced by a high-fat diet (GonzálezRodríguez et al., 2014; Miyagawa et al., 2016; Tanaka et al., 2016), which further demonstrated that autophagosome formation was not changed in response to fatty liver. At least in nonruminants, autophagosome formation-related gene expression is regulated by several transcription factors, including transcription factor $\mathrm{EB}$ and peroxisome proliferator-activated receptor $\alpha$ (Settembre et al., 2011; Lee et al., 2014). It is noteworthy, however, that the expression of both transcription factor EB and peroxisome proliferator-activated receptor $\alpha$ was lower in mice and dairy cows with fatty liver (Du et al., 2017a; Kim et al., 2017; Zhang et al., 2018). Other regulators of autophagosome formation in nonruminants include serum insulin level, AMPactivated protein kinase, and mammalian target of rapamycin (Madrigal-Matute and Cuervo, 2016; Ueno and Komatsu, 2017). Taken together, the multiplicity of factors that could potentially control autophagosome formation-related gene expression between healthy cows and those with fatty liver is clearly large. Future studies clearly are needed to better understand the regulation of autophagosome formation.

Microtubule-associated protein 1 light chain 3 (LC3) and p62 have been widely used as markers for the evaluation of autophagic activity (Mizunoe et al., 2018). Protein expression of LC3 is known to exist in 2 forms: LC3-I, which is found in the cytoplasm, and LC3-II, which is membrane bound and is converted from LC3-I to initiate formation and lengthening of the autophagosome (Hwang et al., 2017). In our study, the protein expression of LC3-II and the number of autophagosomes were greater in the liver of dairy cows 
with severe fatty liver compared with healthy cows. Work in nonruminants revealed that enhanced autophagosome formation leads to an increase in protein expression of LC3-II and number of autophagosomes (Hwang et al., 2017; Mizunoe et al., 2018). Blockade of autophagic activity also results in accumulation of LC3-II and autophagosomes (González-Rodríguez et al., 2014; Ueno and Komatsu, 2017). The expression of autophagosome formation-related genes was unchanged between these 2 groups. Therefore, increased hepatic LC3-II and autophagosomes in dairy cows with severe fatty liver indicate that the autophagosomes were accumulated and that autophagic activity was blockaded. The accumulation of p62 and ubiquitinated proteins in cows with severe fatty liver supports the blockade of autophagic activity. Ubiquitination of misfolded proteins is a prerequisite for autophagic degradation (Czaja et al., 2013). The p62 protein was identified as an autophagy receptor, which binds both ubiquitinated proteins and LC3-II, for autophagic degradation of ubiquitinated targets (Bjørkøy et al., 2005; Mizunoe et al., 2018). It has been shown that activation of autoph- agic activity leads to a decrease in protein expression of p62, whereas accumulation of p62 reflects a blockade of the autophagic activity (González-Rodríguez et al., 2014). Hence, taken together, the accumulation of $\mathrm{p} 62$, LC3-II, ubiquitinated proteins, and autophagosomes in cows with severe fatty liver indicates an impairment of hepatic autophagic activity.

Failure to properly execute the autophagic program leaves hepatocytes vulnerable to stressors and unable to accommodate cellular needs for energy substrates when faced with negative nutrient balance. Previous studies in mice reported that blocked autophagy resulted in enhanced caspase- 1 activation and increased IL-1 $\beta$ production and secretion (Nakahira et al., 2011; Zhou et al., 2011; Zhong et al., 2016). In addition, induction of autophagy with rapamycin inhibits the secretion of IL-13 in murine dendritic cells (Harris et al., 2011). Autophagy also removes aggregated inflammasome structures, thus contributing to dampening proinflammatory responses (Shi et al., 2012; Netea-Maier et al., 2016). Previous studies reported that autophagy prevented cell death and that proper autophagic activity decreased
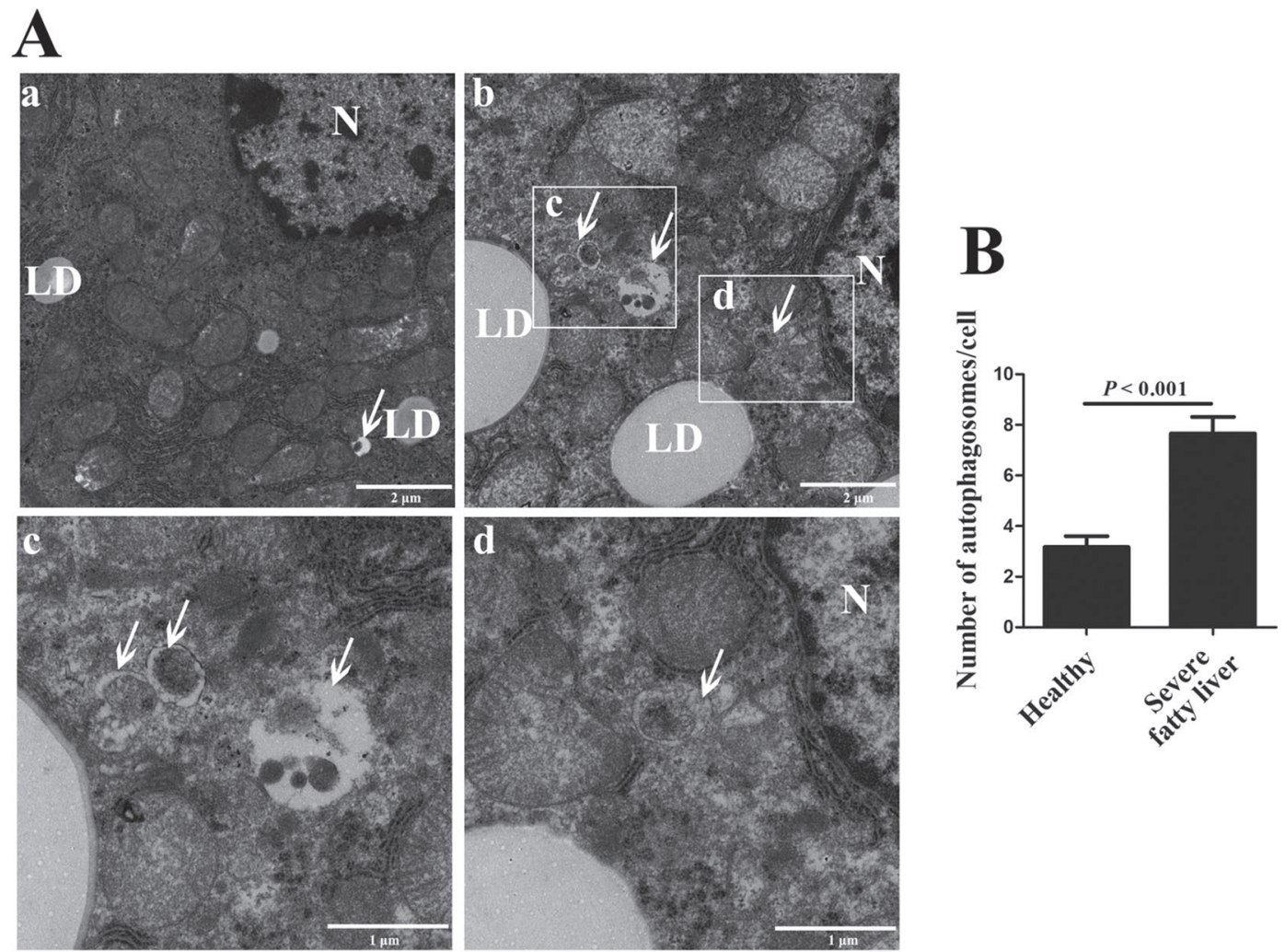

N, Nucleus; LD, Lipid Droplet

Figure 5. Representative transmission electron microscopy images of liver sections (A) Representative images of autophagosomes (white arrows) from healthy cows (a) and cows with severe fatty liver (b, c, d). Scale bars: $2 \mu \mathrm{m}$ (a, b), $1 \mu \mathrm{m}$ (c, d). (B) Number of autophagosomes per cell. Autophagosomes were counted from at least 15 random cells in each sample and expressed as the number of autophagosomes per cell. Data were analyzed with paired $t$-tests and expressed as the mean \pm SEM. 
palmitic acid-induced Huh7 cell apoptosis and high-fat diet-induced liver damage in mice (González-Rodríguez et al., 2014; Liu et al., 2016; Ueno and Komatsu, 2017). These responses in mice undergoing hepatic lipidosis are similar to the greater blood concentrations of inflammatory markers (SAA and HP) and activities of liver damage indicators (AST, ALT, GLDH, and GGT) in cows with severe fatty liver. Therefore, together these data indicated that dysfunction of autophagy could activate the inflammatory response and alter liver function.

\section{CONCLUSIONS}

Impaired hepatic autophagic activity in cows with severe fatty liver is associated with liver lipid accumulation, systemic inflammation, and liver damage. As such, impairment of autophagic activity may be a cause of severe fatty liver. Our findings provide new insights regarding the role of autophagy in metabolic homeostasis of dairy cows with severe fatty liver.

\section{ACKNOWLEDGMENTS}

This work was supported by the National Key Research and Development Program (Beijing, China; grant no. 2016YFD0501206), the National Natural Science Foundation of China (Beijing, China; grant no. $31472247,31572581,31672621$, and 31772810 ), the Jilin Province Science Foundation for Youths (Changchun, China; grant no. 20160520063JH), and the Jilin Natural Science Foundation (Changchun, China; grant no. 20170101148JC). The authors declare no competing financial interests.

\section{REFERENCES}

Backues, S. K., D. Chen, J. Ruan, Z. Xie, and D. J. Klionsky. 2014 Estimating the size and number of autophagic bodies by electron microscopy. Autophagy 10:155-164.

Bjørkøy, G., T. Lamark, A. Brech, H. Outzen, M. Perander, A. Overvatn, H. Stenmark, and T. Johansen. 2005. p62/SQSTM1 forms protein aggregates degraded by autophagy and has a protective effect on huntingtin-induced cell death. J. Cell Biol. 171:603-614.

Bobe, G., J. W. Young, and D. C. Beitz. 2004. Invited review: Pathology, etiology, prevention, and treatment of fatty liver in dairy cows. J. Dairy Sci. 87:3105-3124.

Connor, E. E., R. L. T. Baldwin, A. V. Capuco, C. M. Evock-Clover, S. E. Ellis, and K. S. Sciabica. 2010. Characterization of glucagonlike peptide 2 pathway member expression in bovine gastrointestinal tract. J. Dairy Sci. 93:5167-5178.

Czaja, M. J., W. X. Ding, T. M. Donohue Jr., S. L. Friedman, J. S. Kim, M. Komatsu, J. J. Lemasters, A. Lemoine, J. D. Lin, J. H. Ou, D. H. Perlmutter, G. Randall, R. B. Ray, A. Tsung, and X. M. Yin. 2013. Functions of autophagy in normal and diseased liver. Autophagy 9:1131-1158.

Du, X., L. Chen, D. Huang, Z. Peng, C. Zhao, Y. Zhang, Y. Zhu, Z. Wang, X. Li, and G. Liu. 2017a. Elevated apoptosis in the liver of dairy cows with ketosis. Cell. Physiol. Biochem. 43:568-578.
Du, X., T. Shen, H. Wang, X. Qin, D. Xing, Q. Ye, Z. Shi, Z. Fang, Y Zhu, Y. Yang, Z. Peng, C. Zhao, B. Lv, X. Li, G. Liu, and X. Li. 2018a. Adaptations of hepatic lipid metabolism and mitochondria in dairy cows with mild fatty liver. J. Dairy Sci. 101:9544-9558.

Du, X., Z. Shi, Z. Peng, C. Zhao, Y. Zhang, Z. Wang, X. Li, G. Liu, and X. Li. 2017b. Acetoacetate induces hepatocytes apoptosis by the ROS-mediated MAPKs pathway in ketotic cows. J. Cell. Physiol. 232:3296-3308.

Du, X., Y. Zhu, Z. Peng, Y. Cui, Q. Zhang, Z. Shi, Y. Guan, X. Sha, T. Shen, Y. Yang, X. Li, Z. Wang, X. Li, and G. Liu. 2018b. High concentrations of fatty acids and beta-hydroxybutyrate impair the growth hormone-mediated hepatic JAK2-STAT5 pathway in clinically ketotic cows. J. Dairy Sci. 101:3476-3487.

Edmonson, A. J., I. J. Lean, L. D. Weaver, T. Farver, and G. Webster. 1989. A body condition scoring chart for Holstein dairy cows. J. Dairy Sci. 72:68-78.

Esposito, G., P. C. Irons, E. C. Webb, and A. Chapwanya. 2014. Interactions between negative energy balance, metabolic diseases, uterine health and immune response in transition dairy cows. Anim. Reprod. Sci. 144:60-71.

González-Rodríguez, A., R. Mayoral, N. Agra, M. P. Valdecantos, V. Pardo, M. E. Miquilena-Colina, J. Vargas-Castrillon, O. Lo Iacono, M. Corazzari, G. M. Fimia, M. Piacentini, J. Muntane, L. Bosca, C. Garcia-Monzon, P. Martin-Sanz, and A. M. Valverde. 2014. Impaired autophagic flux is associated with increased endoplasmic reticulum stress during the development of NAFLD. Cell Death Dis. 5:e1179.

Harris, J., M. Hartman, C. Roche, S. G. Zeng, A. O'Shea, F. A. Sharp, E. M. Lambe, E. M. Creagh, D. T. Golenbock, J. Tschopp, H. Kornfeld, K. A. Fitzgerald, and E. C. Lavelle. 2011. Autophagy controls IL-1beta secretion by targeting pro-IL-1beta for degradation. J. Biol. Chem. 286:9587-9597.

Hayirli, A., R. R. Grummer, E. V. Nordheim, and P. M. Crump. 2002. Animal and dietary factors affecting feed intake during the prefresh transition period in Holsteins. J. Dairy Sci. 85:3430-3443.

Hwang, C. J., Y. E. Kim, D. J. Son, M. H. Park, D. Y. Choi, P. H. Park, M. Hellstrom, S. B. Han, K. W. Oh, E. K. Park, and J. T. Hong. 2017. Parkin deficiency exacerbate ethanol-induced dopaminergic neurodegeneration by P38 pathway dependent inhibition of autophagy and mitochondrial function. Redox Biol. 11:456-468.

Kim, K. H., Y. T. Jeong, H. Oh, S. H. Kim, J. M. Cho, Y. N. Kim, S. S. Kim, D. H. Kim, K. Y. Hur, H. K. Kim, T. Ko, J. Han, H L. Kim, J. Kim, S. H. Back, M. Komatsu, H. Chen, D. C. Chan, M. Konishi, N. Itoh, C. S. Choi, and M. S. Lee. 2013. Autophagy deficiency leads to protection from obesity and insulin resistance by inducing Fgf21 as a mitokine. Nat. Med. 19:83-92.

Kim, S. H., G. Kim, D. H. Han, M. Lee, I. Kim, B. Kim, K. H. Kim, Y. M. Song, J. E. Yoo, H. J. Wang, S. H. Bae, Y. H. Lee, B. W. Lee, E. S. Kang, B. S. Cha, and M. S. Lee. 2017. Ezetimibe ameliorates steatohepatitis via AMP activated protein kinase-TFEB-mediated activation of autophagy and NLRP3 inflammasome inhibition. Autophagy 13:1767-1781.

Kuhla, B., D. Albrecht, S. Kuhla, and C. C. Metges. 2009. Proteome analysis of fatty liver in feed-deprived dairy cows reveals interaction of fuel sensing, calcium, fatty acid, and glycogen metabolism. Physiol. Genomics 37:88-98.

Lee, J. M., M. Wagner, R. Xiao, K. H. Kim, D. Feng, M. A. Lazar, and D. D. Moore. 2014. Nutrient-sensing nuclear receptors coordinate autophagy. Nature 516:112-115.

Lei, L., Y. Zhu, W. Gao, X. Du, M. Zhang, Z. Peng, S. Fu, X. Li, W Zhe, X. Li, and G. Liu. 2016. Alpha-lipoic acid attenuates endoplasmic reticulum stress-induced insulin resistance by improving mitochondrial function in HepG2 cells. Cell. Signal. 28:1441-1450.

Li, X., W. Huang, J. Gu, X. Du, L. Lei, X. Yuan, G. Sun, Z. Wang, X. $\mathrm{Li}$, and G. Liu. 2015. SREBP-1c overactivates ROS-mediated hepatic NF-kappaB inflammatory pathway in dairy cows with fatty liver. Cell. Signal. 27:2099-2109.

Li, Y., S. Xu, A. Giles, K. Nakamura, J. W. Lee, X. Hou, G. Donmez, J. Li, Z. Luo, K. Walsh, L. Guarente, and M. Zang. 2011. Hepatic overexpression of SIRT1 in mice attenuates endoplasmic reticulum stress and insulin resistance in the liver. FASEB J. 25:1664-1679. 
Liu, T. Y., X. Q. Xiong, X. S. Ren, M. X. Zhao, C. X. Shi, J. J. Wang, Y. B. Zhou, F. Zhang, Y. Han, X. Y. Gao, Q. Chen, Y. H. Li, Y. M. Kang, and G. Q. Zhu. 2016. FNDC5 alleviates hepatosteatosis by restoring AMPK/mTOR-mediated autophagy, fatty acid oxidation, and lipogenesis in mice. Diabetes 65:3262-3275.

Loor, J. J., M. Bionaz, and J. K. Drackley. 2013. Systems physiology in dairy cattle: Nutritional genomics and beyond. Annu. Rev. Anim. Biosci. 1:365-392.

Loor, J. J., R. E. Everts, M. Bionaz, H. M. Dann, D. E. Morin, R. Oliveira, S. L. Rodriguez-Zas, J. K. Drackley, and H. A. Lewin. 2007. Nutrition-induced ketosis alters metabolic and signaling gene networks in liver of periparturient dairy cows. Physiol. Genomics 32:105-116.

Loos, B., A. du Toit, and J. H. Hofmeyr. 2014. Defining and measuring autophagosome flux - Concept and reality. Autophagy 10:20872096.

Lum, J. J., R. J. DeBerardinis, and C. B. Thompson. 2005. Autophagy in metazoans: Cell survival in the land of plenty. Nat. Rev. Mol. Cell Biol. 6:439-448.

Madrigal-Matute, J., and A. M. Cuervo. 2016. Regulation of liver metabolism by autophagy. Gastroenterology 150:328-339.

Martinez-Lopez, N., M. Garcia-Macia, S. Sahu, D. Athonvarangkul, E. Liebling, P. Merlo, F. Cecconi, G. J. Schwartz, and R. Singh. 2016. Autophagy in the CNS and periphery coordinate lipophagy and lipolysis in the brown adipose tissue and liver. Cell Metab. 23:113-127.

Martinez-Lopez, N., and R. Singh. 2015. Autophagy and lipid droplets in the liver. Annu. Rev. Nutr. 35:215-237.

Miyagawa, K., S. Oe, Y. Honma, H. Izumi, R. Baba, and M. Harada. 2016. Lipid-induced endoplasmic reticulum stress impairs selective autophagy at the step of autophagosome-lysosome fusion in hepatocytes. Am. J. Pathol. 186:1861-1873.

Mizunoe, Y., M. Kobayashi, Y. Sudo, S. Watanabe, H. Yasukawa, D. Natori, A. Hoshino, A. Negishi, N. Okita, M. Komatsu, and Y. Higami. 2018. Trehalose protects against oxidative stress by regulating the Keap1-Nrf2 and autophagy pathways. Redox Biol. 15:115-124.

Mizushima, N. 2005. The pleiotropic role of autophagy: From protein metabolism to bactericide. Cell Death Differ. 12(Suppl. 2):15351541.

Mizushima, N., B. Levine, A. M. Cuervo, and D. J. Klionsky. 2008. Autophagy fights disease through cellular self-digestion. Nature 451:1069-1075.

Morey, S. D., L. K. Mamedova, D. E. Anderson, C. K. Armendariz, E. C. Titgemeyer, and B. J. Bradford. 2011. Effects of encapsulated niacin on metabolism and production of periparturient dairy cows. J. Dairy Sci. 94:5090-5104.

Nakahira, K., J. A. Haspel, V. A. Rathinam, S. J. Lee, T. Dolinay, H. C. Lam, J. A. Englert, M. Rabinovitch, M. Cernadas, H. P. Kim, K. A. Fitzgerald, S. W. Ryter, and A. M. Choi. 2011. Autophagy proteins regulate innate immune responses by inhibiting the release of mitochondrial DNA mediated by the NALP3 inflammasome. Nat. Immunol. 12:222-230.

Netea-Maier, R. T., T. S. Plantinga, F. L. van de Veerdonk, J. W. Smit, and M. G. Netea. 2016. Modulation of inflammation by autophagy: Consequences for human disease. Autophagy 12:245-260.

Sathyanarayan, A., M. T. Mashek, and D. G. Mashek. 2017. ATGL promotes autophagy/lipophagy via SIRT1 to control hepatic lipid droplet catabolism. Cell Reports 19:1-9.

Schiaffino, S., C. Mammucari, and M. Sandri. 2008. The role of autophagy in neonatal tissues: Just a response to amino acid starvation? Autophagy 4:727-730.
Schneider, J. L., and A. M. Cuervo. 2014. Liver autophagy: Much more than just taking out the trash. Nat. Rev. Gastroenterol. Hepatol. 11:187-200.

Sciarretta, S., P. Zhai, D. Shao, D. Zablocki, N. Nagarajan, L. S. Terada, M. Volpe, and J. Sadoshima. 2013. Activation of NADPH oxidase 4 in the endoplasmic reticulum promotes cardiomyocyte autophagy and survival during energy stress through the protein kinase RNA-activated-like endoplasmic reticulum kinase/eukaryotic initiation factor 2alpha/activating transcription factor 4 pathway. Circ. Res. 113:1253-1264.

Settembre, C., C. Di Malta, V. A. Polito, M. Garcia Arencibia, F. Vetrini, S. Erdin, S. U. Erdin, T. Huynh, D. Medina, P. Colella, M. Sardiello, D. C. Rubinsztein, and A. Ballabio. 2011. TFEB links autophagy to lysosomal biogenesis. Science 332:1429-1433.

Shi, C. S., K. Shenderov, N. N. Huang, J. Kabat, M. Abu-Asab, K A. Fitzgerald, A. Sher, and J. H. Kehrl. 2012. Activation of autophagy by inflammatory signals limits IL-1beta production by targeting ubiquitinated inflammasomes for destruction. Nat. Immunol. 13:255-263.

Singh, R., and A. M. Cuervo. 2011. Autophagy in the cellular energetic balance. Cell Metab. 13:495-504

Song, Y., N. Li, J. Gu, S. Fu, Z. Peng, C. Zhao, Y. Zhang, X. Li, Z. Wang, X. Li, and G. Liu. 2016. $\beta$-Hydroxybutyrate induces bovine hepatocyte apoptosis via an ROS-p38 signaling pathway. J. Dairy Sci. 99:9184-9198.

Sun, X., X. Yuan, L. Chen, T. Wang, Z. Wang, G. Sun, X. Li, X. Li, and G. Liu. 2017. Histamine induces bovine rumen epithelial cell inflammatory response via NF- $\mathrm{B}$ pathway. Cell. Physiol. Biochem. 42:1109-1119.

Tanaka, S., H. Hikita, T. Tatsumi, R. Sakamori, Y. Nozaki, S. Sakane, Y. Shiode, T. Nakabori, Y. Saito, N. Hiramatsu, K. Tabata, T. Kawabata, M. Hamasaki, H. Eguchi, H. Nagano, T. Yoshimori, and T. Takehara. 2016. Rubicon inhibits autophagy and accelerates hepatocyte apoptosis and lipid accumulation in nonalcoholic fatty liver disease in mice. Hepatology 64:1994-2014.

Ueno, T., and M. Komatsu. 2017. Autophagy in the liver: Functions in health and disease. Nat. Rev. Gastroenterol. Hepatol. 14:170-184.

Weber, C., C. Hametner, A. Tuchscherer, B. Losand, E. Kanitz, W. Otten, S. P. Singh, R. M. Bruckmaier, F. Becker, W. Kanitz, and H. M. Hammon. 2013. Variation in fat mobilization during early lactation differently affects feed intake, body condition, and lipid and glucose metabolism in high-yielding dairy cows. J. Dairy Sci. 96:165-180.

Yang, L., P. Li, S. Fu, E. S. Calay, and G. S. Hotamisligil. 2010. Defective hepatic autophagy in obesity promotes ER stress and causes insulin resistance. Cell Metab. 11:467-478.

Yorimitsu, T., and D. J. Klionsky. 2005. Autophagy: Molecular machinery for self-eating. Cell Death Differ. 12(Suppl. 2):1542-1552.

Zhang, H., S. Yan, B. Khambu, F. Ma, Y. Li, X. Chen, J. A. Martina, R. Puertollano, Y. Li, N. Chalasani, and X. M. Yin. 2018. Dynamic MTORC1-TFEB feedback signaling regulates hepatic autophagy, steatosis and liver injury in long-term nutrient oversupply. Autophagy 14(28):1-17.

Zhong, Z., E. Sanchez-Lopez, and M. Karin. 2016. Autophagy, inflammation, and immunity: A troika governing cancer and its treatment. Cell 166:288-298.

Zhou, R., A. S. Yazdi, P. Menu, and J. Tschopp. 2011. A role for mitochondria in NLRP3 inflammasome activation. Nature 469:221-225. 